\title{
ANÁLISE DO PROCESSO DE GESTÃO ESTRATÉGICA: UM ESTUDO COMPARATIVO EM ESCRITÓRIOS DE CONTABILIDADE
}

\author{
ANALYSIS OF THE STRATEGIC MANAGEMENT PROCESS: A \\ COMPARATIVE STUDY IN ACCOUNTING OFFICES
}

\section{ANÁLISIS DEL PROCESO DE GESTIÓN ESTRATÉGICA: UN ESTUDIO COMPARATIVO EN OFICINAS DE CONTABILIDAD}

\begin{abstract}
SILVANA ANITA WALTER, DRA.
Professora do Programa de Pós-Graduação em Administração (PPGAD) da Universidade Regional de Blumenau (FURB). Doutora em Administração pela Pontifícia Universidade Católica do Paraná (PUCPR). Mestra em Administração pela Universidade Regional de Blumenau. Atua na linha de pesquisa Estratégia e Competitividade (FURB), estudando preferencialmente Strategy as Practice aliada a Abordagem Institucional e, Ensino e Pesquisa em Administração e Contabilidade. Autora de 20 artigos publicados em periódicos, 6 capítulos de livros, 62 trabalhos apresentados em eventos. Áreas de Atuação: Strategy as Practice e Ensino e Pesquisa em Administração e Contabilidade. Professora do PPGAd - Líder do Tema 4 - Formação do Professor e do Pesquisador EPQ/ANPAD. Endereço: Universidade Regional de Blumenau - FURB Câmpus I - sala D-102. Fone: (47) 33210285/ 3321-0591 - (47) 9629- 6515. Currículo completo disponível em: http://lattes.cnpq.

br/6055446867536139. E-mail: silvanaanita.walter@gmail.com
\end{abstract}

\section{ANA PAULA CAPUANO DA CRUZ}

Atualmente é Doutoranda em Controladoria e Contabilidade pela Universidade de São Paulo - FEA/USP (início em 2010), Bolsista de Doutorado do CNPq e Pesquisadora do Laboratório de Pesquisas sobre Práticas Gerenciais da FEAVUSP. É Mestre em Contabilidade pela Universidade Federal do Paraná - UFPR (2008-2010), Especialista em Ciências Contábeis pela Universidade Federal do Rio Grande - FURG (2006-2008) e Graduada em Ciências Contábeis também pela FURG (2001-2005). Atua, principalmente, nas linhas de pesquisa de Controle Gerencial e Ensino e Pesquisa em Contabilidade. Currículo completo disponível em:

http://lattes.cnpq.br/8832489532145248. E-mail: anapaulacapuanocruz@hotmail.com. 


\section{MÁRCIA MARIA DOS SANTOS BORTOLOCCI ESPEJO}

Coordenadora e professora do Programa de Mestrado em Contabilidade da Universidade Federal do Paraná - UFPR, e docente do curso de Ciências Contábeis da Universidade Federal do Paraná - UFPR. É líder do grupo de pesquisa (CNPq) Laboratório de Controle Gerencial e Teorias Organizacionais Aplicadas. Doutora em Controladoria e Contabilidade pela Universidade de São Paulo -FEA/USP (2005-2008), mestre em Administração pela Universidade Estadual de Londrina - UEL (2002-2004), graduada em Administração pela Universidade Estadual de Maringá (1993-1997). Tem experiência na área de Administração, com ênfase em Ciências Contábeis, atuando principalmente nos seguintes temas: ensino e pesquisa em contabilidade, controle e contabilidade gerencial, gestão orçamentária e análise das demonstrações contábeis. Currículo completo disponível em http://lattes.cnpq. br/2126687770271963. E-mail:marciabortolocci@ufpr.br.

\section{RESUMO}

Este estudo objetiva analisar o processo de gestão de escritórios de contabilidade, especificamente a gestão estratégica, a partir de base teórica que abrange atitude empreendedora; conteúdo e desenvolvimento de estratégias; e contexto de referência. Realizouse, em outubro de 2009, um estudo de caso comparativo de dois escritórios de contabilidade estabelecidos em Curitiba (PR), desenvolvendo-se entrevistas semiestruturadas com os proprietários-dirigentes e análise de conteúdo. Identificou-se a ocorrência de diferentes processos de desenvolvimento de estratégias, sobretudo o incremental e de atitude empreendedora. O conteúdo da estratégia variou de analítico a prospector. $\mathrm{O}$ contexto de referência é, principalmente, o local. Percebeu-se que a atitude empreendedora afeta o conteúdo da estratégia; e que aspectos de atitude empreendedora, conteúdo da estratégia e contexto ambiental de referência interagem e influenciam o processo de desenvolvimento de estratégia. No geral, os resultados obtidos corroboram o encontrado na literatura. Todos os aspectos concluídos apontam para a importância de considerar tais fatores contingenciais (estratégia, ambiente e comportamento empreendedor) para a compreensão do modus operandi do processo de desenvolvimento da estratégia nas organizações, inclusive as tipicamente contábeis.

Palavras-chave: Estratégia; Escritórios de Contabilidade; Empreendedorismo; Ambiente de Referência. 


\section{ABSTRACT}

This study aims to examine the management process of accounting offices, specifically their strategic management, from a theoretical standpoint that broaches the entrepreneurial attitude; content and development of strategies; and reference context. In October 2009, a comparative case study was conducted on two accounting offices in Curitiba (PR), using semi-structured interviews with CEO-managers and a content analysis. The incidence of different strategic development processes, especially the incremental strategy, was identified, as was the entrepreneurial attitude. The strategy content ranged from the analytical to the prospector. The reference of context is, primarily, the location. It was noted that the entrepreneurial attitude affects the strategy's content; and that the aspects of the entrepreneurial attitude, strategic content, and the environmental context of the reference point interact and influence the strategic development process. In general, the obtained results corroborate those which were found in literature. All the concluded aspects point to the importance of considering such contingent factors (strategy, environment, and entrepreneurial behavior) in understanding the modus operandi of the strategic development process of organizations, including those which are typically related to accounting.

Keywords: Strategy; Accounting Offices; Entrepreneurship; Environmental Reference Point.

\section{RESUMEN}

Este estudio objetiva analizar el proceso de gestión de oficinas de contabilidad, específicamente la gestión estratégica, a partir de base teórica que abarca actitud emprendedora; contenido y desarrollo de estrategias; y contexto de referencia. Fue realizado, en octubre de 2009, un estudio de caso comparativo de dos oficinas de contabilidad establecidas en Curitiba (PR), desarrollándose entrevistas semiestructuradas con los propietarios-dirigentes y análisis de contenido. Fue identificada la ocurrencia de diferentes procesos de desarrollo de estrategias, sobretodo el de incremento, y de actitud emprendedora. El contenido de la estrategia varió de analítico a prospectivo. El contexto de referencia y, principalmente, el local. Se percibió que la actitud emprendedora afecta al contenido de la estrategia; y que aspectos de actitud emprendedora, contenido de la estrategia y contexto ambiental de referencia interactúan e influencian el proceso de desarrollo de estrategia. En general, los resultados obtenidos corroboran lo encontrado en la literatura. Todos los aspectos concluidos apuntan hacia la importancia de considerar tales factores de contingencia (estrategia, ambiente y comportamiento emprendedor) para la comprensión del modus operandi del proceso de desarrollo de la estrategia en las organizaciones, inclusive las típicamente contables.

Palabras clave: Estrategia; Oficinas de Contabilidad; Emprendedorismo; Ambiente de Referencia. 


\section{INTRODUÇÃO}

A Contabilidade contribui para a gestão das organizações, fornecendo diversas ferramentas que podem ser empregadas para facilitar e melhorar esse processo. Nesse sentido, Branco (2006) destaca que a Contabilidade representa fonte de informações para diversos tipos de agentes, cooperando para a compreensão da realidade na qual estão inseridos. Além disso, a Contabilidade propicia a operacionalização e o entendimento da tríade mensuração-processamento-comunicação da informação, representando a linguagem dos negócios (HORNGREN; HARRISON JR.; ROBINSON, 1996) e uma espécie de suporte à gestão empresarial. Sob essa perspectiva, entre outras atribuições, espera-se que a Contabilidade gere condições para que os planos gerenciais sejam atingidos nas organizações.

O conjunto de atividades que são desenvolvidas no sentido de assegurar que esses planos sejam atingidos representa o controle gerencial (ANTHONY; GOVINDARAJAN 2008), ou seja, um processo por meio do qual os gestores influenciam membros da organização para implementar suas estratégias. Adicionalmente, os autores esclarecem que o controle gerencial ocupa posição intermediária entre dois outros procedimentos fundamentalmente relevantes às organizações: (a) o controle de tarefas, que exibe caráter bastante sistemático e orientado para o curto prazo, e (b) a formulação de estratégias - processo de natureza menos sistemática, e ligado a perspectiva de longo prazo. Enquanto a formulação da estratégia está fortemente ligada ao processo de planejamento, o controle de tarefas está associado com processos de controles, porém, ambos têm importância ímpar para o controle gerencial das organizações (ANTHONY; GOVINDARAJAN, 2008).

Assim, se a Contabilidade fornece ferramentas que auxiliam no processo de gestão das organizações, por outro lado, percebe-se a importância de analisar como os indivíduos com formação e experiência nessa área atuam como gestores e fazem uso de instrumentos gerenciais. Diante do apresentado, este estudo tem por objetivo analisar o processo de gestão de escritórios de Contabilidade, nos quais os contadores atuam como gestores, especificamente no que tange à gestão estratégica, envolvendo assim aquele procedimento apontado por Anthony e Govindarajan (2008) como intimamente relacionado com o controle gerencial.

Em face do exposto, tem-se, como pergunta de pesquisa: Como ocorre o processo de gestão estratégica em escritórios de Contabilidade de Curitiba, Paraná? Assim, este estudo está focado no processo de gestão estratégica em escritórios de Contabilidade da cidade de Curitiba, Paraná, integrando a este o desenvolvimento de estratégias, os aspectos de atitude empreendedora, o conteúdo da estratégia e o contexto ambiental de referência. A maior parte dessas categorias analíticas já foi estudada em artigos relacionados com gestão estratégica de forma isolada. Nesse sentido, Gimenez (1998) analisou as estruturas cognitivas adotadas por dirigentes de pequenas empresas na administração estratégica de seus negócios, bem como o papel da turbulência ambiental na escolha de 
estratégias, empregando o modelo de conteúdo da estratégia. Gimenez e Gimenez (2010), por sua vez, procuraram identificar a atitude empreendedora dos dirigentes de pequenos e médios hotéis e suas estratégias de atuação no mercado hoteleiro. Ainda, Machado-daSilva e Barbosa (2002) buscaram verificar os fatores e os valores subjacentes de competitividade instituídos no contexto ambiental. Complementarmente, pretende-se contribuir com uma visão mais abrangente, integrando os quatro elementos e sua relação com a estratégia das organizações, o que poderá fornecer informações relevantes sobre esse processo.

O presente estudo encontra-se estruturado em cinco seções, incluindo esta introdução, assim distribuídas: na segunda seção, apresenta-se a base teórica acerca dos aspectos aqui expostos; na terceira, discorre-se sobre o delineamento metodológico empregado; na quarta, apresentam-se os dados coletados e sua análise por meio da técnica de análise de conteúdo; e, na quinta, as considerações finais a respeito deste estudo. Ao final, listamse as referências utilizadas no artigo.

\section{BASE TEÓRICA}

Nesta seção, apresenta-se a base teórica sobre o processo de desenvolvimento de estratégia, considerando também, neste estudo, aspectos como atitude empreendedora, conteúdo da estratégia e contexto ambiental de referência.

O processo de desenvolvimento de estratégias é abordado por Bailey e Avery (1998) por meio de seis dimensões que procuram abranger diferentes influências ocorridas durante esse processo. As seis dimensões destacadas pelos autores são denominadas planejamento, incremental, cultural, política, comando e escolha imposta. Os autores ainda destacam, em relação a cada uma dessas dimensões, como ocorre o desenvolvimento da estratégia, bem como outras características.

Na dimensão planejamento, de acordo com Bailey e Avery (1998), a estratégia é desenvolvida por meio de um processo de planejamento analítico, intencional e sequencial. Além disso, tem-se, nessa dimensão, que: (a) as estratégias da organização são o resultado de procedimentos metódicos, planejados, sequenciais e racionais; (b) os objetivos estratégicos são estabelecidos pelos executivos seniores; (c) a organização e o ambiente são analisados; (d) são estabelecidos objetivos definidos e precisos; (e) são desenvolvidos planos precisos para implementação; e (f) a estratégia é explicitada na forma de planos detalhados (BAILEY; AVERY, 1998).

A segunda dimensão, incremental, refere-se, segundo Bailey e Avery (1998), à estratégia desenvolvida de maneira evolutiva e proposital por um processo de interação e adaptação de tentativa e erro. Como outras características dessa dimensão, os autores citam que: (a) a estratégia é ajustada continuamente para se adequar às mudanças no ambiente operacional; (b) o ajuste das opções estratégicas é avaliado continuamente; 
(c) o compromisso inicial com uma estratégia é incerto e sujeito à revisão; (d) a estratégia é desenvolvida por experimentação e implementação gradual; (e) opções prósperas ganham recursos adicionais; e (f) a estratégia é desenvolvida por meio de mudanças em pequena escala.

Na dimensão cultural, terceira dimensão apontada por Bailey e Avery (1998), a estratégia é dirigida e guiada por aspectos culturais e pela cultura das organizações, bem como pelas suposições e convicções partilhadas por seus membros. Os autores também apontam que nessa dimensão: (a) o "modo de fazer as coisas" da organização impacta na direção estratégica; (b) as estratégias evoluem conforme um conjunto de suposições compartilhadas que existem na organização; (c) um conjunto central de suposições compartilhadas, baseado na experiência e na história da organização, guia ações estratégicas; (c) a história organizacional dirige a procura para a seleção de opções estratégicas; e (d) a estratégia não ajustada à cultura da organização encontra resistência.

Para Bailey e Avery (1998), na quarta dimensão, política, a estratégia é desenvolvida por um processo de barganha, negociação e influência entre os grupos de interesses internos às organizações. As outras características destacadas pelos autores para essa dimensão são: (a) as estratégias são desenvolvidas por meio de negociação e barganha entre grupos; (b) os grupos de interesses buscam atingir seus próprios objetivos; (c) a influência em formulação de estratégia aumenta com o poder; (d) o poder vem da habilidade de criar ou de controlar o fluxo de recursos escassos; (e) os grupos de interesses formam alianças para promover a estratégia desejada por eles; (f) o controle e a provisão de informação também são uma fonte de poder; e (g) uma estratégia aceitável aos grupos de interesses mais poderosos é desenvolvida.

Na dimensão de comando, a quinta, a estratégia é definida e determinada por um indivíduo poderoso da organização (BAILEY; AVERY, 1998). Além disso, os autores ressaltam que: (a) um indivíduo é a força motriz por trás da estratégia da organização; (b) a estratégia é principalmente associada ao poder institucional de um grupo individual ou pequeno; (c) a estratégia representa as aspirações desse indivíduo para o futuro da organização; (d) o indivíduo se torna a representação da estratégia para a organização; e (e) um indivíduo tem um alto grau de controle sobre a estratégia.

A sexta e última dimensão, escolha imposta, aponta, sob a ótica de Bailey e Avery (1998), que a estratégia é resultado de pressões externas às organizações que restringem a habilidade destas para determinar sua própria direção estratégica. Como características dessa dimensão têm-se também que: (a) as estratégias são prescritas pelo ambiente operacional; (b) a escolha estratégica é restringida por forças externas que a organização é incapaz de controlar; (c) a mudança estratégica é instigada de fora da organização; (d) as organizações não podem influenciar seus ambientes operacionais; e (e) as barreiras no ambiente restringem amplamente a mobilidade estratégica. 
A partir da breve exposição das seis dimensões de Bailey e Avery (1998), por meio das quais se desenvolve estratégia, percebe-se uma diversidade de concepções a respeito do desenvolvimento de estratégias, fornecendo, assim, uma base abrangente para analisar como isso ocorre nas organizações. Ressalta-se que essas dimensões variam de acordo com a orientação estratégica da organização e que não são mutuamente excludentes, ou seja, em uma organização podem ser encontradas características de diferentes dimensões.

Para analisar a gestão estratégica e o processo de desenvolvimento de estratégias de forma mais abrangente, tem-se a concepção de que seja importante considerar alguns aspectos relacionados a ela, como a atitude empreendedora (subseção 2.1), o conteúdo da estratégia (subseção 2.2) e o contexto ambiental de referência (subseção 2.3), como serão destacados a seguir.

\subsection{Atitude Empreendedora}

Nos estudos sobre empreendedorismo, há um debate em torno da definição de empreendedor. Para muitos pesquisadores, o indivíduo é ou não é empreendedor. Carland, Carland e Hoy (1992), ao contrário, sugerem que o empreendedorismo poderia ser, na realidade, um continuum, ou seja, que existem diferentes níveis de empreendedorismo, com possibilidade de evolução durante a trajetória. Adotando essa perspectiva, Carland, Carland e Hoy (1992) propuseram um modelo conceitual que busca entender as diferentes categorias de empreendedores, de acordo com a força empreendedora de cada indivíduo. Para Gimenez e Gimenez (2010), no modelo proposto por Carland, Carland e Hoy (1992), a categorização dos indivíduos baseia-se nos objetivos esperados para o futuro empreendimento.

Carland, Carland e Hoy (1992) realizaram uma ampla revisão de literatura que Ihes permitiu perceber que o comportamento empreendedor está associado, principalmente, a quatro elementos - personalidade, propensão para a inovação, propensão ao risco e postura estratégica -, os quais foram empregados para elaboração de seu modelo conceitual.

Gimenez e Gimenez (2010) procuraram descrever e detalhar os quatro elementos apontados por Carland, Carland e Hoy (1992). O elemento personalidade relaciona-se à necessidade de realização e à criatividade. Indivíduos com maior necessidade de realização possuem maior propensão a assumir tarefas difíceis e metas de longo prazo, além de costumeiramente possuírem maior preocupação em atingir a excelência em suas atividades (GIMENEZ; GIMENEZ, 2010). Já a criatividade, segundo estes autores, pode ser percebida principalmente na resolução de problemas, por meio da forma com que o empreendedor aplica seu conhecimento e suas habilidades, bem como por sua motivação para a ação.

O segundo elemento, propensão para a inovação, está intimamente relacionado ao empreendedorismo e pode ser percebido na capacidade de identificar e aproveitar as oportunidades (GIMENEZ; GIMENEZ, 2010). Conforme os autores, pessoas mais empreendedoras provavelmente buscarão produtos e processos distintos dos produzidos e empregados anteriormente. 
A propensão ao risco, terceiro elemento da base conceitual de Carland, Carland e Hoy (1992), é definida por Gimenez e Gimenez (2010) como uma tendência de evitar ou aceitar situações de incerteza em relação aos resultados. Nessas situações, os indivíduos mais empreendedores possivelmente terão maior probabilidade de aceitar os riscos e sentirão menor desconforto diante da presença destes (GIMENEZ; GIMENEZ, 2010).

Por fim, a postura estratégica relaciona-se à existência ou não de pensamento em longo prazo e de monitoramento do contexto, principalmente em relação às condições sociais e econômicas e de envolvimento em atividades de planejamento formal (GIMENEZ; GIMENEZ, 2010). Para os autores, é possível perceber a postura empreendedora da pessoa por meio da forma como identifica uma oportunidade, organiza e aplica os recursos para transformá-la em produtos ou serviços.

Como o presente estudo envolve empresas de pequeno porte, acredita-se ser relevante analisar a atitude empreendedora dos dirigentes e sua relação com a gestão estratégica da organização, visto que estes normalmente são os principais responsáveis pelo desenvolvimento de estratégias nesse tipo de organização. Percebe-se, assim, que o modelo de Carland, Carland e Hoy (1992) pode ser útil para analisar a gestão estratégica de organizações, especialmente por meio da avaliação do elemento de postura estratégica. Gimenez e Gimenez (2010), por exemplo, identificaram uma associação positiva entre atitude empreendedora e estratégia competitiva.

\subsection{Conteúdo da Estratégia}

Miles e Snow (1978) apresentam quatro tipos de comportamento estratégico: defensivo, prospector, analítico e reativo. Essa tipologia tem despertado o interesse de pesquisadores em administração estratégica por se tratar de uma classificação abrangente e que possibilita uma análise do comportamento organizacional, independente do tamanho da organização (VASCONCELOS; GUEDES; CÂNDIDO, 2005).

Gimenez (1998) empregou os quatro tipos de estratégias genéricas citados por Miles e Snow (1978) em seu estudo, sintetizando-os como pode ser observado no Quadro 1.

\section{Quadro 1 - Tipologia de estratégias genéricas de Miles e Snow (1978)}

\begin{tabular}{|l|l|}
\hline Categoria estratégica & \multicolumn{1}{c|}{ Descrição } \\
\hline \multirow{2}{*}{ Estratégia defensiva } & $\begin{array}{l}\text { Uma empresa, seguindo essa estratégia, procura localizar e manter uma linha de } \\
\text { produtos/serviços relativamente estável. Seu foco concentra-se em uma gama } \\
\text { de produtos/serviços mais limitada do que de seus concorrentes e tenta prote- } \\
\text { ger seu domínio por meio da oferta de produtos com melhor qualidade, serviços } \\
\text { superiores e/ou menores preços. Não procura estar entre os líderes da indústria, } \\
\text { restringindo-se àquilo que sabe fazer tão bem ou melhor que qualquer um. }\end{array}$ \\
\hline
\end{tabular}




\begin{tabular}{|l|l|}
\hline \multirow{E}{*}{ Estratégia prospectora } & $\begin{array}{l}\text { Uma empresa que adota essa estratégia está continuamente ampliando sua } \\
\text { linha de produtos/serviços. Enfatiza a importância de oferecer novos produ- } \\
\text { tos/serviços em uma área de mercado relativamente mais ampla. Valoriza } \\
\text { ser uma das primeiras a oferecer novos produtos, mesmo que todos os es- } \\
\text { forços não se mostrem altamente lucrativos. }\end{array}$ \\
\hline Estratégia analítica & $\begin{array}{l}\text { Uma empresa que segue essa estratégia tenta manter uma linha limitada de } \\
\text { produtos/serviços relativamente estável e, ao mesmo tempo, tenta adicionar } \\
\text { um ou mais novos produtos/serviços que foram bem-sucedidos em outras } \\
\text { empresas do setor. Em muitos aspectos, é uma posição intermediária entre } \\
\text { as estratégias defensiva e prospectora. }\end{array}$ \\
\hline Estratégia reativa & $\begin{array}{l}\text { A firma que adota uma estratégia reativa exibe um comportamento mais in- } \\
\text { consistente do que os outros tipos. É uma espécie de não-estratégia. Não } \\
\text { arrisca em novos produtos/serviços, a não ser quando ameaçada por com- } \\
\text { petidores. A abordagem típica é esperar para ver e responder somente quan- } \\
\text { do forçada por pressões competitivas para evitar a perda de clientes impor- } \\
\text { tantes e/ou manter lucratividade. }\end{array}$ \\
\hline
\end{tabular}

Fonte: Gimenez (1998, p. 30).

As duas categorias mais contrastantes são a estratégia prospectora, caracterizada pela busca elevada de mercados e inovação de produtos e processos, e a estratégia defensiva, caracterizada por estreitos domínios de produtos/mercados e ampla ênfase em eficiência. A estratégia analítica pode ser vista como um híbrido de estratégia prospectora e defensiva, possuindo componentes de negócios mais dinâmicos e área central de negócios mais estável, tratado de forma prospectora. Finalmente, na estratégia reativa, têm-se as empresas que aparentemente não apresentam estratégias coerentes entre si e com a estrutura da organização. Assim, apresentam uma não-estratégia de reações impulsivas a eventos do ambiente (GIMENEZ, 1998).

Observa-se que os tipos estratégicos configuram os diversos padrões de comportamento adaptativo usado nas organizações, quando estas procuram responder às demandas do ambiente, possuindo cada uma delas uma configuração particular de tecnologia, estrutura e processo, consistentes com suas estratégias (BRUNALDI; JUNGLES, 2005).

Para Gimenez (1998), as estratégias defensivas, prospectoras e analíticas são consideradas formas estáveis de organização. Se ocorrer o alinhamento entre a estratégia escolhida, os processos e as estruturas organizacionais, qualquer uma dessas estratégias poderá transformar a organização em um competidor eficaz, em uma indústria particular. No entanto, o não-alinhamento entre estratégia e estrutura poderá ocasionar a ineficácia naquela indústria, caracterizando formas instáveis de organização, ou seja, resultará na adoção de estratégias reativas.

A tipologia sobre o comportamento estratégico de Miles e Snow (1978) pode contribuir para a análise da gestão estratégica das organizações, visto que o tipo de estratégia 
adotado consiste em um indício importante de como se dinamiza essa gestão, sobretudo no que diz respeito à estruturação de seu plano de ação. Desse modo, as organizações precisam definir seus focos de atuação e a forma como irão prover respostas às demandas do mercado para, assim, desenvolverem suas estratégias. Gimenez (1998) também identificou a existência de relação entre o conteúdo da estratégia e o perfil dos dirigentes de pequenas empresas, visto que a adoção de estratégias prospectoras era preferida por dirigentes com propensão para inovação, enquanto estratégias defensivas eram mais atraentes para indivíduos com um estilo adaptativo de resolução de problemas.

\subsection{Contexto Ambiental de Referência}

O contexto ambiental de referência, para Machado-da-Silva e Fonseca (1999), representa o ambiente ao qual a organização se reporta para incorporar suas concepções e valores, ou seja, evidencia o foco da organização para a tomada de decisões estratégicas. Para esses autores, o contexto de referência pode ser: local, regional, nacional e internacional.

Machado-da-Silva e Fonseca (1993) ressaltam que, mediante a interpretação das demandas competitivas e socioculturais do seu contexto ambiental de referência, a organização se estrutura e define suas estratégias de ação, visando a atender seus interesses. Ratificando tal assertiva, a pesquisa de Cochia e Machado-da-Silva (2004) destaca que as organizações são continuamente influenciadas pela opção por determinado contexto ambiental de referência que, em última análise, definirá o seu posicionamento estratégico em decorrência de pressões contextuais.

De acordo com Ferraz, Kupfer e Haguenauer (1997), a competitividade não deve ser vista apenas do ponto de vista técnico; devem ser conciliados padrões de concorrência e padrões institucionais, já que o ambiente exerce pressão para que as organizações sejam eficientes e eficazes. Da mesma forma, Meyer e Rowan (1977) e Scott (2008) definem o contexto ambiental em termos de ambiente técnico e ambiente institucional. No ambiente técnico, as organizações disponibilizam produtos ou serviços no mercado e obtêm retribuição com base na relação de troca. Já no ambiente institucional, componentes socioculturais ganham importância. Este ambiente caracteriza-se pela existência de regras e exigências sociais à quais as organizações necessitam se ajustar para alcançarem legitimidade e apoio contextual. Assim, de acordo com Machado-da-Silva e Fonseca (1999), enquanto o ambiente técnico condiciona a posição no mercado e o potencial de concorrência de uma determinada organização, o ambiente institucional afeta a legitimidade de suas escolhas e práticas.

O estudo de Cochia (2002) revelou que pequenas empresas parecem reter sua atenção em contextos mais restritos. Assim, o contexto ambiental de referência pode auxiliar na compreensão da gestão estratégica dessas organizações e fundamentalmente no seu processo de desenvolvimento, visto que, como destacam Machado-da-Silva e Fonseca (1999), 
o contexto determina o foco da atenção organizacional e, portanto, refletirá os pressupostos que a organização avaliará para a elaboração de suas estratégias.

Em adição, ressalta-se que os achados de estudos anteriores (MACHADO-DASILVA; FONSECA, 1995; COCHIA, 2002) sinalizam que considerar o contexto ambiental de referência é salutar para compreender o processo de desenvolvimento da estratégia. Machado-da-Silva e Barbosa (2002) identificaram, por exemplo, diferenças nos padrões de competitividade de acordo com o nível contextual em conformidade com o contexto ambiental de referência das organizações. Além disso, o contexto ambiental de referência pode servir como amortecedor, dificultando a apreensão de práticas e valores emergentes em um contexto mais amplo e interferindo na competitividade das organizações (MACHADO-DA-SILVA; FONSECA, 1999).

\section{DELINEAMENTO METODOLÓGICO}

Para atingir os objetivos propostos, lançou-se mão da estratégia de pesquisa de estudo de caso. De acordo com Yin (2003), os estudos de caso consistem em uma investigação empírica de um fenômeno em seu contexto, sobretudo quando os limites entre contexto e fenômeno não estão bem definidos. Na perspectiva de Stake (2005), o estudo de caso, enquanto forma de pesquisa, é definido pelo interesse por um caso individual, e não pelos métodos empregados. Esse autor ressalta que, mesmo nos estudos de caso realizados em mais de um caso simultaneamente, cada caso terá sua investigação centrada nele próprio.

Neste estudo, analisaram-se os casos de dois escritórios de Contabilidade de Curitiba, Paraná. Para isso, adotou-se a abordagem de estudo de caso comparativo que, segundo Yin (2003), difere do estudo de casos múltiplos pelo fato de serem realizadas análises comparativas entre os casos estudados. Para tal, elaborou-se um protocolo de estudo de caso para orientar os pesquisadores na coleta dos dados e ampliar a confiabilidade do estudo (YIN, 2003), incluindo os objetivos da pesquisa, os procedimentos de campo (dados obtidos previamente sobre os escritórios a serem visitados e dirigentes a serem entrevistados), o roteiro de entrevista e a guia para o relatório final (principais aspectos a serem analisados). Ressalta-se que um dos escritórios autorizou, por escrito, a identificação de seu nome (MV) e o outro não (será descrito como Escritório $\mathrm{A}$ ).

Realizou-se a coleta de dados por meio de quatro entrevistas semiestruturadas com quatro proprietários-dirigentes dos dois escritórios de Contabilidade pesquisados, caracterizados como pequenas empresas, uma vez que possuem de 10 a 49 colaboradores (SEBRAE, 2008). As entrevistas foram realizadas em outubro de 2009. Para sua realização, elaborou-se, a partir da base teórica adotada, um roteiro de entrevista (Apêndice A) para analisar a formação de estratégia, bem como os outros três aspectos relacionados a esta: 
atitude empreendedora, conteúdo da estratégia e contexto ambiental de referência. O roteiro de entrevista foi submetido à avaliação por especialistas, sendo que sua versão final contou com 28 perguntas norteadoras sobre âmbito de atuação, atenção a mudanças, esforços de melhoria, os principais concorrentes e ações governamentais mais influentes; ações estratégias e seus resultados; objetivos estratégicos; realização de análise do ambiente; forma de elaboração de estratégias; utilização de planos formais; processo de escolhas estratégicas; inovação de produtos/serviços; viabilidade da inovação; foco da inovação; objetivo da empresa no mercado; barreiras à formulação e implementação de estratégias; acompanhamento das estratégias; planos futuros; opinião do dirigente sobre a necessidade ou não de descrever formalmente planos e objetivos; divisão de tempo do dirigente entre planejar e executar; características individuais do dirigente (praticidade versus criatividade e otimismo versus realismo); como o dirigente acredita que as pessoas o veem; opinião do dirigente sobre riscos e inovação na empresa; objetivo pessoal do dirigente com a empresa; objetivos e prioridades pessoais do dirigente; concepção do dirigente sobre gerenciamento; e diferencial da empresa em relação aos concorrentes. As entrevistas foram gravadas em áudio, gerando 5 h50 de gravação. Na sequência, realizou-se a transcrição das gravações que totalizaram 92 laudas.

Além disso, realizou-se análise documental por meio da consulta a manuais internos, registros históricos e matérias jornalísticas integrantes dos arquivos das empresas para realização da triangulação de dados. Esses documentos forneceram informações sobre o perfil, as inovações, as mudanças, as ações estratégicas e o relacionamento das organizações pesquisadas com outras empresas e entidades.

Para a análise dos dados, optou-se pela análise de conteúdo, sendo que se empregou o procedimento proposto por Straus e Corbin (2008), com o auxílio do software Atlas.ti 5.0. Straus e Corbin (2008) destacam os processos de codificação aberta, codificação axial e codificação seletiva para a análise e a construção de teoria fundamentada a partir de dados qualitativos. O primeiro processo - codificação aberta -, segundo os autores, consiste em um processo analítico dos dados para identificação dos conceitos, suas propriedades e dimensões. A codificação axial, por sua vez, conforme destacam os autores, é um procedimento para relacionar categorias e suas subcategorias, associando as categorias às suas propriedades e dimensões. Já a codificação seletiva, de acordo com os autores, consiste no processo de integrar (construção da teoria) e de refinar a teoria (rever o esquema à procura de consistência interna e de falhas em sua lógica, completar categorias falhas, retirar os excessos e validar o esquema). Straus e Corbin (2008) ressaltam que esses três procedimentos não são passos ou etapas, mas ocorrem concomitantemente. 
No Quadro 2, destacam-se as dimensões avaliadas no estudo.

\begin{tabular}{|c|c|}
\hline Dimensões & Elementos \\
\hline \multirow{7}{*}{$\begin{array}{l}\text { Processo de } \\
\text { desenvolvimento } \\
\text { de estratégia }\end{array}$} & Definição/descrição dos objetivos \\
\hline & Existência e utilização de planos formais \\
\hline & Ajustes/alterações nas estratégias \\
\hline & Participantes das escolhas estratégicas \\
\hline & Análise e relação com o ambiente \\
\hline & Influências/aspectos considerados na formação de estratégias \\
\hline & Relação entre cultura e desenvolvimento de estratégias \\
\hline \multirow{7}{*}{$\begin{array}{l}\text { Atitude } \\
\text { empreendedora } \\
\text { do dirigente }\end{array}$} & Necessidade de realização \\
\hline & Criatividade \\
\hline & Automotivação \\
\hline & Propensão para a inovação \\
\hline & Propensão ao risco \\
\hline & Pensamento estratégico em longo prazo \\
\hline & Monitoramento do ambiente \\
\hline \multirow{4}{*}{$\begin{array}{l}\text { Conteúdo da } \\
\text { estratégia }\end{array}$} & Inovações de produtos/serviços \\
\hline & Viabilidade das inovações \\
\hline & Foco das inovações \\
\hline & Objetivo da empresa no mercado \\
\hline \multirow{5}{*}{$\begin{array}{l}\text { Contexto } \\
\text { ambiental } \\
\text { de referência }\end{array}$} & Âmbito (local, regional, nacional e internacional) de atuação \\
\hline & Âmbito das mudanças às quais a organização se mantém mais atenta \\
\hline & Mercado ao qual os esforços de melhoria são direcionados \\
\hline & Âmbito de atuação dos principais concorrentes \\
\hline & Âmbito das ações governamentais mais influentes \\
\hline
\end{tabular}

Quadro 2 - Dimensões e elementos analisados

\section{ANÁLISES DOS DADOS}

Nesta seção, apresenta-se a análise dos dados.

\subsection{Perfil dos escritórios pesquisados}

No Quadro 3, apresenta-se um breve perfil e algumas características dos escritórios pesquisados. 


\section{Quadro 3 - Perfil e algumas características dos escritórios estudados}

\begin{tabular}{|c|c|c|}
\hline Característica & Escritório A & MV \\
\hline Criação & $\begin{array}{l}\text { Com } 56 \text { anos de atuação, iniciou suas ati- } \\
\text { vidades com apenas um sócio fundador. }\end{array}$ & $\begin{array}{l}\text { Atua há } 27 \text { anos, tendo iniciado as ativi- } \\
\text { dades com dois sócios. Posteriormente, } \\
\text { um dos sócios saiu da empresa, e o ir- } \\
\text { mão do outro sócio, que já era funcioná- } \\
\text { rio, assumiu parte na sociedade. }\end{array}$ \\
\hline $\begin{array}{l}\text { Colaboradores } \\
\text { e clientes }\end{array}$ & $\begin{array}{l}\text { Atualmente possui } 30 \text { colaboradores e } 173 \\
\text { clientes (principalmente pessoas jurídicas). }\end{array}$ & $\begin{array}{l}\text { Atualmente possui } 46 \text { colaboradores e, } \\
\text { aproximadamente, } 680 \text { clientes (princi- } \\
\text { palmente pessoas jurídicas). }\end{array}$ \\
\hline Dirigentes & $\begin{array}{l}\text { Sócio fundador, uma filha, um filho e uma } \\
\text { nora. }\end{array}$ & $\begin{array}{l}\text { Sociedade entre dois irmãos e uma "ge- } \\
\text { rente executiva". }\end{array}$ \\
\hline Sede & $\begin{array}{l}\text { Sede alugada de } 500 \mathrm{~m} 2 \text { e está construin- } \\
\text { do uma sede própria que terá } 300 \mathrm{~m} 2 \text {. }\end{array}$ & Sede alugada de $500 \mathrm{~m}^{2}$. \\
\hline $\begin{array}{l}\text { Faturamento } \\
\text { em } 2008\end{array}$ & Aproximadamente $80.000,00$ mensais. & Aproximadamente $170.000,00$ mensais. \\
\hline $\begin{array}{l}\text { Principais } \\
\text { serviços } \\
\text { prestados }\end{array}$ & $\begin{array}{l}\text { Serviços de área fiscal, departamento pesso- } \\
\text { al, constituição de empresas, declaração de } \\
\text { imposto de renda e, principalmente, fiscal. }\end{array}$ & $\begin{array}{l}\text { Serviços de área fiscal, departamento } \\
\text { pessoal, fiscal, contratos, palestras, as- } \\
\text { sessoria para abertura de empresas e } \\
\text { declaração de imposto de renda. }\end{array}$ \\
\hline $\begin{array}{l}\text { Processo } \\
\text { de decisão }\end{array}$ & $\begin{array}{l}\text { As decisões são tomadas conjuntamente } \\
\text { pelos membros da família. }\end{array}$ & $\begin{array}{l}\text { O poder de decisão é compartilhado, } \\
\text { principalmente pelo diretor executivo (um } \\
\text { dos sócios) e pela gerente executiva. }\end{array}$ \\
\hline $\begin{array}{l}\text { Formação } \\
\text { dos dirigentes }\end{array}$ & $\begin{array}{l}\text { Todos os dirigentes são graduados em Ci- } \\
\text { ências Contábeis. }\end{array}$ & $\begin{array}{l}\text { Todos os dirigentes possuem graduação } \\
\text { em Ciências Contábeis ou curso técnico } \\
\text { em Contabilidade. }\end{array}$ \\
\hline $\begin{array}{l}\text { Processo } \\
\text { de sucessão }\end{array}$ & $\begin{array}{l}\text { O processo de sucessão está ocorrendo no } \\
\text { escritório por meio da atuação dos familia- } \\
\text { res, principalmente da filha mais velha. }\end{array}$ & $\begin{array}{l}\text { Nesse escritório, ainda não há sinais de } \\
\text { preocupação com sucessão. }\end{array}$ \\
\hline Parcerias & $\begin{array}{l}\text { Com a Caixa Econômica Federal (Conec- } \\
\text { tividade Social) e principalmente com ad- } \\
\text { vogados (orientação jurídica) e contadores } \\
\text { que atuam com auditoria. }\end{array}$ & $\begin{array}{l}\text { Com faculdades para recrutamento de } \\
\text { funcionários e principalmente com con- } \\
\text { tadores que atuam com auditoria e con- } \\
\text { sultoria na área financeira e na realiza- } \\
\text { ção de treinamentos para funcionários } \\
\text { e clientes. }\end{array}$ \\
\hline
\end{tabular}

Fonte: Dados da pesquisa.

Percebe-se, por meio da análise documental, que o Escritório A consiste em uma empresa mais tradicional no ramo em relação à MV. Ambos podem ser classificados como pequenas empresas, conforme classificação do SEBRAE (2008), visto que possuem entre 
10 e 49 colaboradores, bem como apresentam características peculiares como terem sido criadas para que seus fundadores exercessem sua profissão. Apesar disso, a MV se destaca pelo maior número de colaboradores e, principalmente, de clientes. A esse respeito, ressalta-se que esse escritório anteriormente possuía mais de 50 funcionários e que, contudo, passou por um processo de mudança acentuado nos últimos cinco anos, o qual possibilitou a ampliação do número de clientes e a diminuição do número de colaboradores.

O Escritório A pode ser classificado como empresa familiar, visto que os quatro dirigentes pertencem à mesma família, o processo de decisão ocorre em conjunto entre eles e existe preocupação com a sucessão no negócio. Nesse sentido, ressalta-se, também, que o nome do escritório consiste no sobrenome da família. No entanto, igualmente vale destacar que as funções de cada membro da família são bem definidas, bem como que nem todos familiares trabalham na empresa. É o caso de um dos filhos e do genro do dirigente fundador, sendo que esse genro chegou a atuar no escritório durante um período, mas depois se afastou e abriu seu próprio escritório com foco na prestação de outro tipo de serviço (perícia judicial). Percebe-se, dessa maneira, que essa empresa familiar apresenta características de profissionalização bem delineadas e, atualmente, de descentralização de poder, visto que o dirigente principal compartilha responsabilidades com os demais dirigentes, principalmente com a filha mais velha.

Em contrapartida, a MV, apesar de ser uma sociedade entre dois irmãos, não apresenta muitas características de empresa familiar, visto que um dos três dirigentes não pertence à família e que as decisões não são tomadas exclusivamente pelos seus membros. Existe mais um membro da família dos sócios que atua na empresa - uma irmã destes -, mas que não ocupa cargo gerencial. Além disso, cada irmão desempenha uma função específica: um é "diretor operacional", mais focado no atendimento a clientes, e o outro, "diretor executivo".

Em relação ao foco de atuação e serviços prestados, identificado por meio da pesquisa documental e das entrevistas, destaca-se que o Escritório A atende principalmente pessoas jurídicas, desenvolvendo serviços de escrituração contábil e fiscal; folha de pagamento; planejamento tributário; e constituição de empresas. A empresa também oferece a possibilidade de um funcionário atuar dentro da sede de um cliente (outsourcing), atendendo exclusivamente a ele. As pessoas físicas por sua vez são atendidas principalmente por meio de declaração de impostos de renda; folha de pagamento de empregados domésticos; e escrituração de livro caixa para autônomos. Já a MV também atende principalmente pessoas jurídicas, prestando serviços de Contabilidade, fiscal e departamento pessoal. Esse escritório também atua no desenvolvimento de contratos, assessoria para abertura de empresas e palestras para os clientes nas três áreas. $O$ atendimento a pessoas físicas prestado por esse escritório refere-se mais a realização de declaração de imposto de renda.

Para sua atuação, os escritórios pesquisados desenvolvem parcerias com outras organizações e profissionais. A esse respeito, destaca-se que ambos possuem parcerias 
com contadores que atuam na realização de auditorias. O Escritório A, como identificado na análise documental e ressaltado nas entrevistas, também realizou uma parceira com a Caixa Econômica Federal, em 1998, no projeto piloto do programa Conectividade Social, que consiste em um canal eletrônico de transmissão de informações sobre o recolhimento do Fundo de Garantia do Tempo de Serviço (FGTS) e a respeito da Previdência Social. Esse escritório também possui parcerias com advogados, que realizam consultoria jurídica para seus clientes, bem como indicam clientes potenciais para o escritório. Um dos dirigentes desse escritório destacou, na entrevista, que a maioria dos clientes estrangeiros foi obtida por meio da indicação desses profissionais, visto que ao desejarem instalar uma filial no Brasil, organizações estrangeiras normalmente procuram inicialmente a orientação de advogados, os quais muitas vezes indicam um escritório de Contabilidade. A MV, por outro lado, desenvolve parcerias com empresas de consultoria para realização dos treinamentos oferecidos aos clientes.

Sobre concorrência no mercado de atuação, os dirigentes de ambos os escritórios indicaram que qualquer escritório do município pode ser considerado um concorrente, mas que não existe uma competição acirrada por clientes, pois estes normalmente procuram os escritórios de Contabilidade a partir de indicações.

A respeito da utilização de tecnologias, percebeu-se que não há destaque nos escritórios pesquisados, tendo sido identificados o uso de sistema informatizado, softwares e internet. O Escritório A possui, nesse sentido, o diferencial de possuir softwares instalados diretamente nas unidades de seus clientes.

No tocante à formação dos dirigentes, no Escritório $A$, todos são graduados em Ciências Contábeis, sendo que os filhos e a nora também possuem uma segunda área de formação, como Ciências Econômicas, Inglês e Psicologia. O dirigente principal, fundador, inicialmente era técnico em Contabilidade e, posteriormente, graduou-se na área. Já na MV, o diretor executivo cursou técnico em Contabilidade e graduação em Ciências Contábeis; o diretor operacional também cursou graduação em Ciências Contábeis; e a gerente executiva, que atualmente cursa uma graduação na área de gestão, fez técnico em Contabilidade. Nota-se, assim, que os dirigentes principais dos dois escritórios possuíam, inicialmente, a formação de técnicos em Contabilidade, mas buscaram complementá-la por meio da graduação. Percebe-se também que a principal formação dos dirigentes está relacionada à atuação como contadores e não como gestores, sendo que apenas a gerente executiva da MV está cursando graduação na área de gestão. Apesar disso, os novos dirigentes, principalmente do Escritório $A$, estão investindo em formações em áreas complementares que talvez possam facilitar sua atividade de gestão, incluindo a preocupação com a gestão de pessoas e com o contato com clientes estrangeiros por meio da língua inglesa e italiana. Também não foi identificada a realização de pós-graduação lato sensu ou stricto sensu. 
Nos dois escritórios analisados, pelo menos um dos fundadores ainda está em atuação, demonstrando que ainda não sofreram processo de sucessão completo. O Escritório A atua há mais tempo e está com o processo sucessório encaminhado, destacando-se a atuação da filha mais velha, que começou a participar da empresa dez anos antes dos demais membros da família. Além disso, o dirigente principal convidou o neto que está por iniciar o curso de direito para atuar na empresa. Já na MV, ainda não existe um possível sucessor, o que pode estar relacionado ao fato de esta atuar a menos tempo e, portanto, seus dirigentes ainda não terem sentido a necessidade de sucessão. Além disso, a MV possui menos características de empresa familiar.

\subsection{Processo de desenvolvimento de estratégias}

O Quadro 4 apresenta a análise do processo de desenvolvimento de estratégias dos dois escritórios estudados.

\section{Quadro 4 - Análise do processo de desenvolvimento de estratégias dos escritó- rios estudados}

\begin{tabular}{|c|c|c|}
\hline Dimensão & Escritório A & MV \\
\hline Comando & $\begin{array}{l}\text { Anteriormente à entrada dos filhos e da nora, } \\
\text { o dirigente fundador era responsável por to- } \\
\text { das as decisões tomadas no escritório, bem } \\
\text { como por controlar as ações realizadas. }\end{array}$ & $\begin{array}{l}\text { Dimensão não detectada, pois os ob- } \\
\text { jetivos estratégicos são definidos em } \\
\text { conjunto pelos dirigentes e muitas es- } \\
\text { tratégias são discutidas e alteradas com } \\
\text { subgerentes. }\end{array}$ \\
\hline Escolha imposta & $\begin{array}{l}\text { Também anteriormente à entrada dos filhos } \\
\text { e da nora, parte das estratégias do escritório } \\
\text { costumava ser resultado de reações a pres- } \\
\text { sões externas ou necessidades internas. }\end{array}$ & $\begin{array}{l}\text { Dimensão não detectada, visto que não } \\
\text { foi identificada a adoção de estratégias } \\
\text { em virtude de pressões externas. }\end{array}$ \\
\hline Planejamento & $\begin{array}{l}\text { As decisões são tomadas pelos dirigentes } \\
\text { principais do escritório e transmitidas aos } \\
\text { demais. Contudo, não existem planos forma- } \\
\text { lizados nem estratégias em longo prazo. }\end{array}$ & $\begin{array}{l}\text { As metas e objetivos são definidos pelos } \\
\text { dirigentes. O escritório possui um plane- } \\
\text { jamento anual que é elaborado no início } \\
\text { do ano e avaliado no término do período. }\end{array}$ \\
\hline Cultural & $\begin{array}{l}\text { O escritório possui uma cultura muito forte ba- } \\
\text { seada em sua história, tradição, nome, "modo } \\
\text { de fazer", postura religiosa e postura ética. }\end{array}$ & $\begin{array}{l}\text { O escritório alia a tradição do nome com } \\
\text { a inovação em sua cultura, mas não fo- } \\
\text { ram identificadas convicções amplamen- } \\
\text { te arraigadas. }\end{array}$ \\
\hline Incremental & $\begin{array}{l}\text { Notaram-se aspectos incrementais como a } \\
\text { emergência de ideias no decorrer do pro- } \\
\text { cesso e experimentação. }\end{array}$ & $\begin{array}{l}\text { Perceberam-se aspectos incrementais } \\
\text { como ajuste contínuo, implementação } \\
\text { gradual e revisão de estratégias. }\end{array}$ \\
\hline
\end{tabular}

Fonte: Dados da pesquisa. 
Verifica-se, por meio do Quadro 4, que as estratégias são desenvolvidas nos escritórios pesquisados por meio de diferentes processos, não sendo possível identificar apenas a ocorrência de desenvolvimento de estratégias por meio de processo político.

Observa-se, particularmente sobre o Escritório A, que, durante o período de atuação deste, aconteceram alterações na forma como ocorre o processo de desenvolvimento de estratégias. Assim, anteriormente à entrada dos filhos e da nora nesse escritório, foi possível identificar o desenvolvimento de estratégias por meio de dimensões como comando e escolha imposta. O processo de comando pode ser verificado pelo fato de que, nesse período, o poder de controle e de decisão estava concentrado em seu dirigente fundador, que tomava todas as decisões individualmente, ou seja, como destacado por Bailey e Avery (1998), a estratégia era definida e determinada por um indivíduo poderoso da organização. No que tange às escolhas impostas, o dirigente fundador do Escritório A apontou a influência de forças externas que afetam decisões do escritório e não podem ser controladas por este. Nesse sentido, destaca-se o momento no qual o prédio em que o escritório tinha sua sede foi vendido, fazendo com que tivesse que deixar o endereço. Essa ocorrência, alheia aos desejos do escritório, impulsionou-o a comprar uma sede. Assim, a escolha estratégica foi determinada por forças externas que a organização é incapaz de controlar (BAILEY; AVERY, 1998). Atualmente o escritório está em uma sede alugada, mas está construindo uma sede própria.

No que tange ao planejamento, verifica-se que, nos dois escritórios, os dirigentes principais definem os objetivos estratégicos da empresa. Contudo, isso não é realizado por meio de planos formalizados, analíticos, intencionais e sequenciais (BAILEY; AVERY, 1998). Isso porque, apesar de ser identificado na análise documental que a MV possui um plano anual, no qual, no momento da coleta de dados, algumas das estratégias para 2009 já estavam definidas, não foram encontrados planos formais. Ressalta-se, também em relação à análise documental, que a maioria dos objetivos e metas é de curto prazo e que os objetivos em longo prazo não possuem data definida, etapas, ferramentas ou mecanismos por meio do quais possam ser atingidos, como o caso da sede própria do Escritório A, ou seja, os objetivos em longo prazo ainda são vagos.

Outro aspecto percebido foi a presença, no Escritório A, do processo cultural, no qual a estratégia é dirigida pela cultura das organização, bem como pelas suposições e convicções partilhadas por seus membros (BAILEY; AVERY, 1998). Esse escritório possui uma cultura forte, visto que se fundamenta em sua história, tradição, nome, "modo de fazer", postura religiosa e postura ética. Essa característica pode ser exemplificada por meio de falas dos dirigentes, como "isso é algo que se conquista com o tempo", "é constante, desde o princípio, trabalhar com correção, com honestidade", "nossos clientes confiam em nós, alguns preferem deixar cheques assinados no nosso cofre para pagarmos seus impostos", bem como por práticas existentes, como a de destinar um momento durante a semana para 
que todos do escritório se reúnam para orar. Já, na MV, há uma miscigenação entre tradição no mercado e inovação de serviços e de atendimento. No entanto, não foram identificadas convicções amplamente arraigadas ou compartilhadas entre os membros.

A esse respeito, observa-se que o tempo maior de atuação do Escritório A pode ter favorecido o desenvolvimento dessa cultura que transpassa, muitas vezes, o processo de desenvolvimento de estratégias. Nesse sentido, percebe-se que esse escritório possui convicções que são compartilhadas por seus dirigentes e estão relacionadas à cultura da empresa. Assim, pedidos de clientes que contrariam essas convicções são rejeitados, mesmo que causem a perda do cliente. Dessa forma, percebem-se indícios de que uma convicção da organização, ou seja, sua preocupação com a ética pode influenciar o desenvolvimento de estratégias. Como Bailey e Avery (1998) destacam que a estratégia pode ser guiada por aspectos culturais das organizações, bem como pelas convicções partilhadas por seus membros.

É possível observar, também, que muitas das estratégias e mudanças apontadas pelos dirigentes foram desenvolvidas de forma incremental, ou seja, por meio de experimentação, revisão e ajuste de estratégias; e implementação gradual (BAILEY; AVERY, 1998). Como exemplo pode-se citar que, no Escritório A, a primeira tentativa de informatização falhou, como notado na análise documental e nas entrevistas. Os dirigentes apontam que algumas ideias surgem no decorrer do processo e são avaliadas pelos dirigentes para decidir sobre a implementação ou não. Na MV, destaca-se o ajuste contínuo das estratégias por meio de reuniões semanais envolvendo a direção e os subgerentes, a implementação das mudanças em etapas e a necessidade de revisão de estratégias. Após implantar, por exemplo, um novo sistema com várias ferramentas de trabalho, percebeu-se a necessidade de verificar por que os colaboradores não estavam utilizando várias dessas ferramentas. Assim, a estratégia de utilização desse sistema necessitou ser revista para criar ações que estimulassem a adesão dos colaboradores.

\subsection{Atitude empreendedora}

No Quadro 5, apresenta-se a análise da atitude empreendedora dos dirigentes dos dois escritórios pesquisados..

\section{Quadro 5 - Análise da atitude empreendedora dos dirigentes dos escritórios estudados}

\begin{tabular}{|c|c|l|}
\hline Elemento & \multicolumn{1}{|c|}{ Escritório A } & \multicolumn{1}{c|}{ MV } \\
\hline Personalidade & $\begin{array}{l}\text { Não foi possível identificar características desse } \\
\text { elemento entre os dirigentes do Escritório A. }\end{array}$ & $\begin{array}{l}\text { Os dirigentes apresentam característi- } \\
\text { cas como criatividade, automotivação e } \\
\text { necessidade de autorrealização. }\end{array}$ \\
\hline
\end{tabular}




\begin{tabular}{|l|l|l|}
\hline $\begin{array}{l}\text { Propensão } \\
\text { à inovação }\end{array}$ & $\begin{array}{l}\text { Por meio da atuação dos filhos e nora do diri- } \\
\text { gente fundador, ocorreram muitas mudanças } \\
\text { e foram promovidas inovações. }\end{array}$ & $\begin{array}{l}\text { Ainovação em serviços parece ser a carac- } \\
\text { terística mais marcante desse escritório. }\end{array}$ \\
\hline $\begin{array}{l}\text { Propensão } \\
\text { ao risco }\end{array}$ & $\begin{array}{l}\text { Ocorre propensão ao risco no que tange à } \\
\text { realização de empréstimos. }\end{array}$ & $\begin{array}{l}\text { A propensão ao risco está relacionada } \\
\text { às mudanças e à inovação em serviços. }\end{array}$ \\
\hline $\begin{array}{l}\text { Postura } \\
\text { estratégica }\end{array}$ & $\begin{array}{l}\text { Não foram identificados estratégias em longo } \\
\text { prazo ou monitoramento do contexto. }\end{array}$ & $\begin{array}{l}\text { Não foi identificada a realização de mo- } \\
\text { nitoramento do contexto, mas os dirigen- } \\
\text { tes estão procurando desenvolver estra- } \\
\text { tégias de longo prazo. }\end{array}$ \\
\hline
\end{tabular}

Fonte: Dados da pesquisa.

O Quadro 5 indica que a atitude empreendedora dos dirigentes dos escritórios estudados é bastante distinta, bem como que eles apresentam algumas características empreendedoras e outras não.

Quanto à personalidade, os dirigentes da MV apresentam a característica de necessidade de autorrealização, como pode ser percebido na fala de um dos dirigentes: "quero uma excelente Contabilidade, só" e "nós vamos ser uma referência em Curitiba, escreva isso, estou te falando". A característica de criatividade também pode ser verificada no tocante a esse escritório, visto os diversificados mecanismos, identificados na análise documental, serem implementados para manter os colaboradores motivados e produtivos como atesta a fala de um deles: "a gente tem que surpreender o cliente, eu penso assim". Tem-se ainda, nos dirigentes desse escritório, a característica de automotivação, como denota a seguinte fala de um deles a respeito do processo para certificação ISO, que a empresa já tinha iniciado duas vezes sem concluí-lo: "aí eu falei, então vamos lá, agora vai sair, custe o que custar". Dessa forma, esse dirigente decidiu retomar esse processo e concluí-lo, automotivando-se para tal. Não foi possível identificar a existência dessas características nos dirigentes do Escritório $A$.

No que tange à propensão para a inovação, no Escritório A, principalmente a partir da entrada dos filhos e da nora, foram promovidas a informatização e a aquisição de equipamentos, a adesão ao programa Conectividade Social da Caixa Econômica Federal e o atendimento a empresas estrangeiras, como verificado na análise documental e nas entrevistas. Quanto à MV, a inovação nos serviços prestados parece ser sua característica mais marcante, visto que promoveu a extinção dos departamentos por meio de uma reestruturação em "miniescritórios", de forma que cada contador ou pequeno grupo de contadores, até três, é responsável por atender seus clientes em todas as áreas (como financeira, gerencial, tributária e pessoal, além das orientações de natureza jurídica); criou um serviço de atendimento ao cliente (SAC); e extinguiu o arquivo dentro do escritório. A empresa também 
presta serviços diferenciados, como treinamentos para clientes. Esses aspectos também foram encontrados tanto na análise documental quanto na indicação dos entrevistados.

A respeito da propensão ao risco, esta pode ser percebida no Escritório A devido à realização de empréstimos para a aquisição de equipamentos, conforme notado na análise documental e retomado nas entrevistas. Já a MV aponta assumir riscos relacionados a mudanças e inovações, e não à realização de empréstimos, visto que os dirigentes indicam, nas entrevistas, evitá-los em virtude dos juros.

No que tange à postura estratégica, definida por Gimenez e Gimenez (2010) como a existência de pensamento em longo prazo e de monitoramento do contexto, muitos aspectos já foram ressaltados no Quadro 2. Ressalta-se que não foi identificada a realização de monitoramento do contexto em nenhum dos escritórios, nem estratégias de longo prazo no Escritório A. Contudo, vale destacar que os dirigentes da MV apontaram nas entrevistas que atualmente estudam estratégias de longo prazo, como a possibilidade de atuar em dois turnos, de modo que possam ampliar o quadro de colaboradores para atender ao aumento no número de clientes, otimizando o espaço físico já existente e ampliando os lucros. Além disso, pretendem atuar com maior intensidade no endereço dos clientes, melhorando o atendimento e ampliando a satisfação destes.

Outro aspecto que pode ser destacado em relação ao perfil empreendedor, consiste no fato de os dirigentes principais do Escritório A terem desenvolvido um novo empreendimento paralelo durante sua trajetória na empresa de Contabilidade. Uma estratégia que também pode ser destacada consiste na implantação da ISO 9000 como instrumento para a melhoria do processo de gestão; no entanto, o Escritório A não concluiu o processo de certificação e, portanto, como verificado na análise documental, apenas a MV a mantém.

\subsection{Conteúdo da estratégia}

No que tange ao conteúdo da estratégia, o Escritório A caracteriza-se mais por uma atitude analítica, embasada na qualidade dos serviços, analisando as possibilidades e as oportunidades de inovação antes de sua efetiva implantação. Segundo Gimenez (1998), empresas que adotam predominantemente uma estratégia analítica costumam possuir componentes de negócios mais dinâmicos e área central de negócios mais estável. Destaca-se, ainda, que essa atitude de precaução quanto às inovações e mudanças pode estar relacionada ao fato de que este escritório sofreu grandes prejuízos com a primeira tentativa de informatização que não obteve os resultados esperados.

A MV, apesar de focar a qualidade para obtenção da satisfação dos clientes, destaca-se por seu perfil mais prospector, visto que está continuamente inovando em seus serviços, como pode ser percebido nas palavras de um de seus dirigentes: "Somos inovadores e buscamos a inovação sempre". A estratégia prospectora, de acordo com Gimenez (1998), caracteriza-se pela busca constante na inovação de serviços. Isso pode ser notado pelo 
fato de a MV oferecer uma gama maior de serviços a seus clientes (Quadro 3), bem como alguns diferenciais que poderiam ser considerados inovadores como as palestras.

\subsection{Contexto ambiental de referência}

No Quadro 6, apresenta-se o contexto ambiental de referência dos escritórios analisados.

\section{Quadro 6 - Análise do contexto ambiental de referência}

\begin{tabular}{|l|l|l|}
\hline $\begin{array}{c}\text { Contexto ambiental } \\
\text { de referência }\end{array}$ & \multicolumn{1}{|c|}{ Escritório A } & \multicolumn{1}{c|}{ MV } \\
\hline Local & Curitiba e região metropolitana. & Curitiba e região metropolitana. \\
\hline Regional & Paraná. & Paraná. \\
\hline Nacional & $\begin{array}{l}\text { Santa Catarina, São Paulo, Rio Grande de } \\
\text { Sul, Minas Gerais, Rio de Janeiro e Mato } \\
\text { Grosso. }\end{array}$ & São Paulo e Santa Catarina. \\
\hline Internacional & Holanda e Estados Unidos. & $\begin{array}{l}\text { Não se relaciona com o contexto } \\
\text { internacional. }\end{array}$ \\
\hline
\end{tabular}

Fonte: Dados da pesquisa.

A respeito do contexto ambiental de referência dos escritórios pesquisados, apresentado no Quadro 6, ressalta-se que a atuação é focada, principalmente, no contexto local. No entanto, os escritórios também atendem a filiais instaladas em outros estados, como Santa Catarina, São Paulo, Rio Grande de Sul, Minas Gerais, Rio de Janeiro e Mato Grosso (Escritório A) e São Paulo e Santa Catarina (MV), como identificado na análise documental e comentado pelos dirigentes nas entrevistas. O Escritório A também atende empresas estrangeiras com unidades no Brasil, o que exige que esteja atento à legislação, às exigências e às características internacionais, visto que, como ressalta a dirigente do Escritório A, a moeda, os princípios contábeis e a legislação são diferentes. Como diferencial para atuação com empresas estrangeiras, há o domínio da língua inglesa por um dos filhos do dirigente fundador. Além do mercado de atuação, percebe-se que os escritórios pesquisados também se relacionam com o contexto ambiental de referência nacional, uma vez que são amplamente afetados por alterações na legislação nacional exatamente por estarem situados no setor de serviços contábeis, como indicado pelos dirigentes nas entrevistas.

Sobre os escritórios que atualmente atendem a empresas estrangeiras instaladas no Brasil, pode estar ocorrendo uma ampliação do contexto ambiental de referência, visto que, como destacam os dirigentes entrevistados, o atendimento a empresas internacionais é um processo recente e que, de acordo com Machado-da-Silva e Fonseca (1999), a mudança 
ocorre à medida que novos valores e regras se incorporam ao contexto de referência. Contudo, verifica-se que ainda há um grande caminho a ser percorrido para a internacionalização dos serviços prestados pelos escritórios analisados.

\subsection{Síntese dos resultados}

O histórico e o perfil dos escritórios analisados podem auxiliar a compreender e a explicar o processo de gestão destes, visto que o tempo de atuação, a característica de empresa familiar ou não e características dos dirigentes podem estar relacionados à percepção de que o Escritório A apresenta-se mais conservador e a MV, mais inovadora em serviços.

A atitude empreendedora dos dirigentes fornece indícios relevantes sobre o processo de gestão estratégica, visto que, como observado, são eles que detêm o poder para a tomada de decisão. Uma análise comparativa entre a atitude empreendedora e o conteúdo da estratégia permite perceber que a atitude empreendedora do proprietário dirigente de pequenos escritórios de Contabilidade afeta o conteúdo da estratégia. Isso porque se percebeu que uma atitude mais fortemente empreendedora (MV) leva à adoção de uma estratégia mais inovadora na empresa - o que também foi indicado por Gimenez (1998) -, ao passo que há indícios de que o inverso também seja verdadeiro (Escritório A). Portanto, assim como Gimenez e Gimenez (2010), encontrou-se neste estudo uma relação entre atitude empreendedora dos dirigentes e estratégias de suas organizações.

Em se tratando do contexto ambiental de referência, nota-se que as estratégias são desenvolvidas, em sua maioria, com foco no mercado local, o que corrobora o destacado por Cochia (2002) sobre pequenas empresas. Além disso, os escritórios também necessitam estarem alinhados às regulamentações nacionais e às normas internacionais de Contabilidade, no caso do Escritório A que atende a empresas estrangeiras. Assim, poder-se-ia dizer que, adotando a concepção de Meyer e Rowan (1977) e Scott (2008), os escritórios pesquisados possuem, como ambiente técnico, o contexto ambiental de referência local, visto que é neste que efetivamente atuam, e, como ambiente institucional, o contexto ambiental de referência nacional ou internacional, uma vez que necessitam atender a regras e exigências desses ambientes.

A partir da análise do processo de gestão estratégica dos escritórios de Contabilidade pesquisados, observa-se que as estratégias são, em sua maioria, desenvolvidas de forma incremental, apesar de serem definidas pelos dirigentes principais. Como destaca Quinn (1978), adotando a perspectiva do incrementalismo lógico, as estratégias bem-sucedidas possuem uma abordagem menos racional-analítica e mais evolucionária, fragmentada e altamente intuitiva. Poder-se-ia inferir que a não-adoção de um plano estratégico formal pode favorecer isso, visto que as metas tendem a ficar vagas e que as estratégias são implementadas quando emergem em forma de tentativas e passíveis de revisão. 
Nesse contexto, destaca-se que o processo de gestão estratégica do Escritório A é focado no ambiente local, mas ele se destaca por atender também empresas com filiais em outros estados e empresas estrangeiras com filiais no Brasil. O tipo de estratégia mais adotada é a analítica em relação a possíveis inovações, o que se relaciona ao perfil de seus dirigentes que apresentaram menos elementos de atitude empreendedora. Além disso, destaca-se que o processo de formação de estratégias é principalmente incremental.

A MV, por sua vez, é mais aberta a inovações, desenvolvendo estratégias mais prospectoras e tendo dirigentes com presença de diversos elementos de atitude empreendedora. Essas estratégias são voltadas mais ao ambiente local, atendendo algumas filiais localizadas em outros estados. Em comum com o outro escritório, percebe-se que a gestão estratégica é realizada principalmente de maneira incremental.

\section{CONSIDERAÇÕES FINAIS}

Neste estudo, analisaram-se os casos de dois escritórios de Contabilidade de Curitiba, PR, com o objetivo de verificar como ocorre o processo de gestão estratégica de cada um deles. Para tal, traçou-se o perfil dos mesmos e fez-se a análise do conteúdo das estratégias, da atitude empreendedora e do contexto ambiental de referência.

A partir deste estudo, pode-se, portanto, verificar que os aspectos analisados de atitude empreendedora dos proprietários dirigentes, o conteúdo da estratégia e o contexto ambiental de referência interagem e influenciam o processo de desenvolvimento de estratégia, ou seja, o processo de desenvolvimento de estratégia em pequenas empresas de Contabilidade é influenciado por aspectos como a atitude empreendedora, o conteúdo da estratégia e o contexto ambiental de referência. Essa percepção se mostra mais complexa à medida que o processo de formação de estratégia tem uma ênfase processual, cultural ou analítica, ou outra, dependendo de como se configuram as relações entre atitude empreendedora, pressões percebidas no contexto de referência e estratégia adotada. Como pode ser notado, embora todas as empresas analisadas possam ser consideradas maduras e estáveis, com mais de 20 anos de existência, os processos de formação da estratégia diferenciam-se bastante entre elas. Esse fato parece implicar necessidade de se explorar mais fortemente a influência de várias dimensões, como destacado.

Nota-se, por meio deste estudo, que não é possível aplicar pura e simplesmente uma classificação estanque aos escritórios pesquisados, uma vez que eles apresentam características de diferentes classificações concomitantemente. Essa observação é importante no sentido de demonstrar que se deve evitar classificar organizações e indivíduos de forma fechada, sob rótulos.

Assim, reconhecendo-se a importância de adaptação às mudanças ambientais por meio da exploração das potencialidades das práticas contábeis no que diz respeito ao respaldo demandado por qualquer modificação (OTLEY, 1994), acredita-se que os re- 
sultados do presente estudo auxiliam na visualização de que os benefícios dos serviços contábeis podem ser mais bem explorados de modo a se tornarem mais contributivos à gestão empresarial.

Destaca-se, como limitação deste estudo, que os resultados encontrados não podem ser generalizados para outras empresas. Todavia, acredita-se que o desenvolvimento de pesquisas voltadas à profundidade investigativa pode contribuir sobremaneira para a valorização da prestação de serviços contábeis, uma vez que o estudo de interações e relações de interdependência organizacionais, por meio de um elo com a teoria organizacional como alternativa à análise e diagnóstico de problemas relativos à Contabilidade e às organizações, pode, inclusive, indicar as especificidades dos serviços que o mercado tem demandado.

Sugere-se, para futuras pesquisas, analisar o processo de gestão estratégica envolvendo outras dimensões relacionadas a ele. Esse processo também poderia ser pesquisado em outros escritórios, o que poderia revelar mais estratégias, desenvolvidas de forma política por exemplo, ou a existência de planos estratégicos formais.

\section{REFERÊNCIAS}

ANTHONY, Robert N.; GOVINDARAJAN, Vijay. Sistemas de Controle Gerencial. 12. ed. São Paulo: McGraw-Hill, 2008.

BAILEY, Andy; AVERY, Clare. Discovering and defining the process of strategy development. In: AMBROSINI, Véronique; JOHSON, Gerry; SCHOLES, Kevan (Coord.). Exploring techniques of analysis and evaluation in strategic management. Harlow: Pearson Education, 1998.

BRANCO, Manuel C. Uma Abordagem Institucionalista da Contabilidade. Revista Contabilidade \& Finanças. São Paulo, v. 17, n. 42, p. 104-112, set./dez. 2006.

BRUNALDI, Karla R.; JUNGLES, Antônio E. Avaliação do comportamento estratégico e do estilo cognitivo dos Dirigentes em pequenas empresas construtoras. In: SIMPÓSIO BRASILEIRO DE GESTÃO E ECONOMIA DA CONSTRUÇÃO, 4., 2005, Porto Alegre. Anais... Porto Alegre: ANTAC, 2005.

CARLAND, James W.; CARLAND, Joann C.; HOY, Frank. S. An entrepreneurship index: an empirical validation. Frontiers of Entrepreneurship Research, v. 25, n. 3, p. 244-265, mar. 1992. 
COCHIA, Camila B. R. Contexto ambiental, esquemas interpretativos e posicionamento estratégico: um estudo em pequenas empresas paranaenses. Curitiba, 2002, 205 f. Dissertação (Mestrado em Administração) - Programa de Pós-Graduação em Administração, Universidade Federal do Paraná, Curitiba, 2002.

COCHIA; Camila B. R.; MACHADO-DA-SILVA, Clóvis L. Ambiente, interpretação e estratégia em organizações paranaenses dos setores de vestuário e alimentos. Revista de Administração Contemporânea, v. 8, edição especial, p. 11-35, 2004.

FERRAZ, João C.; KUPFER, David; HAGUENAUER, Lia. Made in Brazil: desafios competitivos para a indústria. Rio de Janeiro: Campus, 1997.

GIMENEZ, Fernando A. P. Escolhas estratégicas e estilo cognitivo: um estudo com pequenas empresas. Revista de Administração Contemporânea, v. 2, n. 1, p. 27-45, jan./abr. 1998.

GIMENEZ, Sara C.; GIMENEZ, Fernando A. P. Atitude empreendedora e estratégia em pequenos e médios hotéis. Revista Turismo Visão e Ação, v. 12, n. 1, p. 49-72, jan./abr. 2010.

HORNGREN, Charles T.; HARRISON JR., Walter T.; ROBINSON, Michael A. Accounting. 3. ed., Upper Addle River: Prentice Hall, 1996.

MACHADO-DA-SILVA, Clóvis L.; BARBOSA, Solange de L. Estratégia, Fatores de Competitividade e Contexto de Referência das Organizações: uma Análise Arquetípica. Revista de Administração Contemporânea, v. 6, n. 3, p. 7-32, set./dez. 2002.

MACHADO-DA-SILVA, Clóvis L.; FONSECA, Valéria S. Estruturação da estrutura organizacional: o caso de uma empresa familiar. Organizações \& Sociedade, v. 1, n. 1, p. 42-71, 1993.

Configuração estrutural da indústria calçadista de Novo Hamburgo. In: FENSTERSEIFER, J. E. (org). O complexo calçadista em perspectiva: tecnologia e competitividade. Porto Alegre: Ortiz, p. 217-245, 1995.

. Competitividade organizacional: conciliando padrões concorrenciais e padrões institucionais. In: VIEIRA, M.; OLIVEIRA, L. M. (orgs.). Administração Contemporânea: perspectivas estratégicas. São Paulo: Atlas, p. 29-39, 1999.

MEYER, John W.; ROWAN, Brian. Institutionalized organizations: formal structure as myth and ceremony. American Journal of Sociology, v. 83, n. 2, p. 340-363, 1977. 


\section{repc}

MILES, Raymond E.; SNOW, Charles C. Organizational strategy, structure and process. New York: McGraw-Hill, 1978.

OTLEY, David. Management control in contemporary organizations: towards a wider framework. Management Accounting Research, v. 5, n. 3-4, p. 289-299, 1994.

QUINN, James B. Strategic Change: “logical incrementalism”. Sloan Management Review, v. 20 , n. 1, p. $7-21,1978$.

SCOTT, W. Richard. Institutions and organizations. 3. ed. London: Sage Publications, 2008.

SEBRAE - Serviço Brasileiro de Apoio às Micro e Pequenas Empresas. Critérios e conceitos para a classificação de empresas. Disponível em: <www.sebrae.com.br>. Acesso em: 31 out. 2008.

STAKE, Robert E. Qualitative case studies. In: DENZIN, N.; LINCOLN, T. Handbook of qualitative research. London: Sage, 2005.

STRAUS, Anselm; CORBIN, Juliet. Pesquisa qualitativa: técnicas e procedimentos para o desenvolvimento de teoria fundamentada. 2. ed., Porto Alegre: Artmed, 2008.

VASCONCELOS, Ana C. F. de; GUEDES, Isabela A.; CÂNDIDO, Gesinaldo, A. Estratégia em pequenas e médias empresas: uma aplicação dos modelos de Miles e Snow e Kirton em um arranjo produtivo local. In: ENCONTRO NACIONAL DE ENGENHARIA DE PRODUÇÃO, 25., 2005, Porto Alegre. Anais... ABEPRO, 2005.

YIN, Robert K. Estudo de caso: planejamento e métodos. 3. ed. Porto Alegre: Bookman, 2003. 


\section{APÊNDICE A - ROTEIRO DE ENTREVISTAS}

\section{ETAPA 1: PERFIL}

\section{Da empresa:}

\section{Nome da Empresa:}

Principal ramo de atividade da empresa (comércio, indústria ou serviços):

Classificação da atividade de acordo com o CNPJ (com código de classificação):

Tempo de existência da empresa (anos e meses):

Número de empregados:

\section{Do(s) dirigente(s):}

Nome:

Cargo:

Sexo:

Idade:

Nível máximo de escolaridade:

\section{ETAPA 2: CONTEXTO DE REFERÊNCIA}

1. Nos últimos anos, a atuação da empresa tem sido mais voltada (clientes) e organizada de acordo com o mercado internacional, nacional, regional ou local?

2. A empresa tem se mantido mais atenta aos comportamentos e as mudanças ocorridas em qual destes quatro mercados (internacional, nacional, regional ou local)? As mudanças e tendências de qual desses mercados são as que mais afetam sua empresa?

3. Os esforços para melhoria são direcionados, em maior número, para qual dos quatro mercados?

4. A maior preocupação de sua empresa tem sido com que tipo de concorrentes (locais, regionais, nacionais ou internacionais)?

5. Na sua opinião, qual deveria ser o foco das ações governamentais (políticas de incentivo, de restrição, de combate, entraves, facilidade de acesso, tributações, subsídios, incentivos fiscais...)? Em que âmbito (local, regional, nacional ou internacional)? 


\section{Pergunta de estímulo a partir da qual serão 'costuradas' as demais etapas:}

- Comente as principais ações que você considera como estratégicas que deram certo nos últimos dois anos. E quais não deram certo?

\section{ETAPA 3: DESENVOLVIMENTO DE ESTRATÉGIA}

1. Os objetivos de sua empresa estão claros e definidos? Existem procedimentos precisos para alcançar os objetivos estratégicos e para encontrar soluções para os problemas estratégicos?

2. A sua empresa costuma fazer análises do ambiente empresarial? Como? Essas análises servem de base para promover mudanças que alinhem a empresa ao ambiente empresarial? O ambiente empresarial limita a liberdade em relação às escolhas estratégicas? A sua empresa influencia o ambiente empresarial ou se protege dele?

3. Com base em que as estratégias são elaboradas? (experiências anteriores, cultura da empresa, práticas da empresa...).

\section{Itens de apoio:}

- Elas são baseadas em experiências anteriores? A história da empresa orienta a busca por soluções para assuntos estratégicos?

- Estão relacionadas à cultura da empresa? Quando uma mudança estratégica contraria a cultura da empresa, essa mudança sofre resistências para ser implementada?

- Existem convicções e suposições que são típicas de sua empresa? As estratégias desenvolvidas pela empresa estão associadas ao modo como as coisas são realizadas na empresa?

4. As estratégias se originam de planos formais ou informais? Como são atualizadas as estratégias?

\section{Itens de apoio:}

- Definidas pelos planos formais? As opções estratégicas são definidas em relação aos objetivos estratégicos definidos formalmente?

- Para desenvolver estratégias, a empresa experimenta e testa novas abordagens do mercado?

- Elas são desenvolvidas por meio de um processo de ajuste contínuo? Aempresa se compromete com as estratégias definidas, mas isso não quer dizer que ela não possa ser revista?

5. Explique como ocorre o processo de escolha das estratégias. Quem costuma definir as estratégias da empresa (pessoa, equipe)? Quem influencia essas escolhas estratégicas? Existe influência externa na definição das estratégias? 


\section{Itens de apoio:}

As estratégias da empresa estão vinculadas essencialmente à visão de uma pessoa, refletem interesses de grupos poderosos ou emergem pela negociação entre grupos e indivíduos, ou seja, consiste no ajuste dos interesses conflitantes de pessoas e grupos poderosos?

No caso das estratégias estarem vinculadas a uma pessoa, essa consiste no executivo principal? Ele costuma consultar a equipe administrativa para definir as estratégias?

No caso de as estratégias se relacionarem a uma pessoa ou a grupos, a influência desses grupos ou dessa pessoa é ampliada pelo controle que possui (em) sobre os recursos críticos para as atividades da empresa?

No caso de existirem influências de outros grupos, esses grupos podem ser externos à empresa?

\section{ETAPA 4: CONTEÚDO DA ESTRATÉGIA}

\section{Inovação de produtos/serviços:}

A sua empresa mantém uma linha de produtos estável [defensiva] ou procura inovar com novos produtos/serviços? Caso sua empresa procure inovar em produtos/serviços, essa inovação é constante (foco da empresa) [prospectora], costuma basear-se em inovações que funcionaram bem em outras empresas do setor [analítica] ou ocorre como resposta a uma ameaça de competidores (a empresa não costuma se arriscar com inovações) [reativa]?

\section{Viabilidade da inovação:}

Quando a empresa está cogitando uma inovação, realiza um estudo para analisar a viabilidade financeira desta? O que determina sua realização ou não [analítica]? Ou a empresa acredita que a inovação traz outras vantagens para a empresa (como imagem) e, portanto, não precisa necessariamente de viabilidade financeira [prospectora]?

\section{Foco da inovação:}

A oferta de produtos/serviços de sua empresa é voltada à inovação (se orgulham em ser os primeiros a oferecer determinado produto/serviço) [prospectora], à qualidade ou preço (fazem aquilo que realmente podem fazer tão bem ou melhor que as demais empresas do setor) [defensiva], aos produtos/serviços bem-sucedidos no setor [analítica] ou às exigências do mercado [reativa]? 


\section{Objetivo da empresa:}

A sua empresa procura ser a líder do mercado [prospectora], fazer aquilo no que apresenta melhor desempenho [defensiva], ser eficiente como as outras empresas que o são no setor [analítica] ou adotar uma postura conservadora, mudando apenas quando necessário para manter a lucratividade ou evitar a perda de clientes importantes [reativa]?

\section{ETAPA 5: ATITUDE EMPREENDEDORA}

1. Na sua opinião, os planos e os objetivos da empresa necessitam estar descritos ou basta estarem delimitados e claros? [postura estratégica]

2. Você investe mais de seu tempo na empresa planejando ou gerenciando? Você se considera, dentro da empresa, a pessoa responsável por pensar e planejar ou mais por realizar?

3. Você se considera uma pessoa habilidosa e prática ou criativa e imaginativa? Por quê? Como você encara as situações e problemas (otimista ou realista)? Procura enxergar possibilidades ou como as coisas são na realidade?

4 Na sua opinião, qual a imagem que as pessoas que trabalham com você têm a seu respeito?

\section{Itens de apoio:}

- esforçado ou de fácil relacionamento?

- elas trabalham muito ou gostam de você?

- você se preocupa com os direitos ou com os sentimentos delas?

5. Qual sua visão a respeito dos riscos? Eles são necessários ou devem ser evitados? Em que situações você assume riscos? [propensão ao risco]

\section{Itens de apoio:}

6. Você gosta de desafios ou prefere estabilidade? Você prefere desafiar os concorrentes ou ter cautela?

7. Você procura inovar ou prefere manter as coisas que vão bem como estão? Procura novas alternativas ou prefere os procedimentos já padronizados? [propensão para a inovação]

8. Seu principal objetivo para empresa é que ela seja a melhor ou que sobreviva? E seu objetivo pessoal é autorrealizar-se ou obter dinheiro? 
9. Quais são seus objetivos e prioridades? Como você divide seu tempo entre trabalho e família/amigos?

\section{Itens de apoio:}

- objetivos pessoais e prioridades estão mais relacionados com a empresa ou com algo externo a ela?

- gasta mais tempo na empresa do que com a família e amigos ou consegue dividir seu tempo entre ambos?

10. Você acredita que gerenciar é uma atividade rotineira ou com mudanças constantes?

11. Em relação à concorrência, o que você considera como um diferencial importante? (atitude do proprietário, eficiência, qualidade e preço justo, imagem...).

\section{Itens de apoio:}

- a atitude do proprietário é fundamental ou o importante é fazer algo melhor do que as outras empresas fazem?

- qualidade e preço justo são os atributos mais importantes para os clientes ou também é necessário ter uma boa imagem?

\section{RESULTADOS E COMENTÁRIOS ADICIONAIS}

1 Quais as principais barreiras encontradas para formulação e para implementação das estratégias?

2 Há acompanhamento das estratégias implementadas? Como são medidos os resultados estratégicos? Existem indicadores?

3 Quais os planos futuros para sua empresa? 